\title{
Rehabilitation for social reintegration in liver transplant patients
}

\author{
Jong Man Kim \\ Department of Surgery, Samsung Medical Center, Sungkyunkwan University School of Medicine, Seoul, Korea
}

Keywords: Liver transplantation; Rehabilitation; Fatigue

\section{See Article on Page 402}

This study is meaningful as the first on return to work of liver transplantation (LT) patients.' Work return after solid organ transplantation is a major goal for adult patients, but employment rates in this population are low. The present study reports a high employment rate (50\%) compared with a previous study (24\%) based on the United Network for Organ Sharing data registry. ${ }^{2}$

Considering the 5 -year survival rate of more than $70 \%$ after LT, returning to normal activity in the work place and quality of life are important for long-term survival of LT patients. Recently, many clinicians in LT have focused on restoring social quality of life $(\mathrm{QOL})$, returning to the work place, and prolonging life expectancy. Accordingly, employment after LT is a recovery target for many patients. For a normal social life after LT, satisfaction, happiness, and emotional stability can be achieved in part through work life. Transplant recipients who return to work generally attain good functional status and QOL; however, failure to obtain or maintain a job, leads to reduced social life and QOL.

Fatigue and weakness are the main symptoms in many LT recipi- ents. The present study also showed that $50 \%$ of liver recipients remain unemployed after $L T$, mostly due to fatigue and muscle weakness. ${ }^{1}$ Therefore, the importance of rehabilitation therapy is emphasized to reduce fatigue and improve performance by increasing muscle mass after LT. A previous study describes how fatigue is improved by a 12 -week rehabilitation program including exercises and physical activity. ${ }^{2}$ Fatigue was analyzed using three validated scales, and the results showed that the rehabilitation program reduced fatigue from $53 \%$ to $22 \%$. $^{3,4}$ Rehabilitation programs should be helpful in social reintegration of LT recipients. However, there are many difficulties in implementing such a program in Korea because they are not covered by insurance.

$\mathrm{LT}$ recipients benefit from returning to work but face barriers in obtaining and maintaining a job. Post-transplant employment rates are limited despite many recipients regaining the ability to work. Socioeconomic and labor market characteristics limit continuous employment of LT recipients. In employed recipients, intermittent attendance, bad working environment, and delayed employment are common after LT. Therefore, good quality jobs are also important.

Further research is needed to identify and facilitate the factors

\section{Abbreviations:}

$\mathrm{LT}$, liver transplantation; QOL, quality of life

\section{Corresponding author : Jong Man Kim}

Department of Surgery, Samsung Medical Center, Sungkyunkwan University School of Medicine, 81 Irwon-ro, Gangnam-gu, Seoul 06351, Korea

Tel: +82-2-3410-1719, Fax: +82-2-3410-0040

E-mail:yjongman21@gmail.com

https://orcid.org/0000-0002-1903-8354 
Jong Man Kim

Rehabilitation in liver transplantation

that enable transplant patients to return to normal life.

\section{Conflicts of Interest}

The author of this manuscript has no conflicts of interest to disclose.

\section{REFERENCES}

1. Kang SH, Choi YR, Han HS, Yoon YS, Cho JY, Kim SH, et al. Fatigue and weakness hinder patient social reintegration after liver transplantation. Clin Mol Hepatol 2018;24:402-408.
2. Huda A, Newcomer R, Harrington C, Blegen MG, Keeffe EB. High rate of unemployment after liver transplantation: analysis of the United Network for Organ Sharing database. Liver Transpl 2012;18:89-99.

3. van den Berg-Emons RJ, van Ginneken BT, Nooijen CF, Metselaar HJ, Tilanus HW, Kazemier G, et al. Fatigue after liver transplantation: effects of a rehabilitation program including exercise training and physical activity counseling. Phys Ther 2014;94:857-865.

4. van Ginneken BT, van den Berg-Emons RJ, van der Windt A, Tilanus HW, Metselaar HJ, Stam HJ, et al. Persistent fatigue in liver transplant recipients: a two-year follow-up study. Clin Transplant 2010;24:E10-E16. 